\title{
Biomechanical justification of the choice of optimum mode for passing the individual pursuit race
}

\author{
Kolumbet A.N. ${ }^{1 \mathrm{BCE}}$, Dudorova L.Y. ${ }^{1 \mathrm{ACE}}$, Babina N.A. ${ }^{2 \mathrm{BCE}}$, Natroshvili S.G. ${ }^{2 \mathrm{ACE}}$, Chernovsky S.M. ${ }^{1 \mathrm{CDE}}$ \\ ${ }^{1}$ Department of Physical Education and Health, Kiev National University of Technology and Design, Ukraine \\ ${ }^{2}$ Department of Economics, Kiev National University of Technology and Design, Ukraine
}

Authors' Contribution: A - Study design; B - Data collection; C - Statistical analysis; D - Manuscript Preparation; E - Funds Collection.

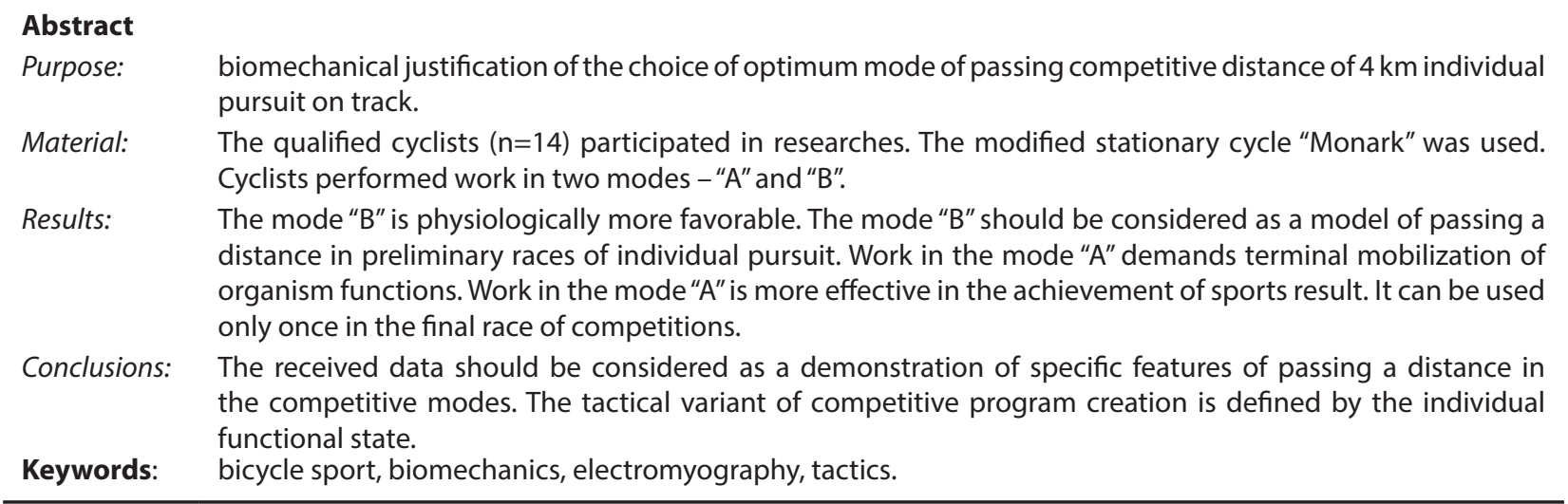

\section{Introduction}

Recently the considerable attention of experts is paid on the development of the optimum structure of athletes' competitive activity. The functionality of the person is fully realized in the competitive exercise by means of sports result [1-3]. The sports result is a systemically important factor which provides selection and degree of involvement in certain components. The research of structure of competitive activity concerns the number of issues of increase in efficiency of the technology of cover a distance. It also allows creating models of optimal technical and tactical variant of conducting a race [4].

In the analysis of competitive activity features are used the approach which consists in the evaluation of the efficiency of covering a certain part of a distance $[5,6]$. Their duration is caused by the length of a distance and dimensions of the sports construction. In this approach, the efficiency of covering a certain part of a distance is completely ignored. The speed of distance at the same time becomes predominating.

Majority of researches conditionally distinguish starting, distant and finishing parts in the structure of competitive activity $[7,8]$. It reflects the result of the most external demonstrations of muscular activity of cyclists. Certain parameters of the athlete organism functioning during cover a competitive distance are connected with sports result. The sports result is set of the interconnected and independent components of competitive activity $[9,10]$. Every component is defined by various motor qualities, abilities, and functional mechanisms.

Such method terminates search of the main regularities of process optimization of sports improvement. The new approach is studying of sports result structure from (c) Kolumbet A.N., Dudorova L.Y., Babina N.A., Natroshvili S.G., Chernovsky S.M., 2018

doi:10.15561/20755279.2018.0203 system positions [11]. This approach presupposes to consider the result as a reflection of complex activity of the vital systems of athlete's organism. Studying of structure competitive activity of highly-qualified athletes from this point of view allows getting more deeply into the structure of sports result $[12,13]$.

The athletic technique is one of the factors which terminate sports result [14]. It is observed the considerable variability of separate elements of motor actions' structure of cyclists in equal working effect. It is defined quantitative and qualitative changes in physical actions structure of cyclists influenced by the set of factors [15]. These factors define external and internal conditions of realization the motor potential of athletes in the course of competitive activity. Winners of top competitions which demand sports endurance don't decrease the speed at the end of a distance and increase it under the condition of the increasing exhaustion [16]. At the same time, the technology of the main sports motor action is significantly changed [17, 18]. However, there is a question: what factors influence on the maintenance of high distance speed in the exhaustion state? [19].

The development of biomechanical prerequisites of optimization of competitive activity structure is important [12, 20, 21]. This problem consists of a wide range of questions. These questions are connected with a search of regularities of demonstration the individual adaptive reactions in the system of motor actions [22]. The differentiated nature of their demonstration depends on the structural features of various physical qualities development [23, 24].

The search of regularities of demonstration the adaptive reorganizations in the system of motor actions will promote the increase in efficiency of cyclists' technical training process. At the same time are considered: specific 
features, level of readiness, specifics of competitive activity structure.

The research hypothesis is the following: it was presupposed that the biomechanical and electromyographic analysis of cyclists pedalling technique in $4 \mathrm{~km}$ individual pursuit race allow setting the most optimum mode of passing a distance.

The purpose of the research is biomechanical reasons of the choice of optimum mode of passing competitive distance of $4 \mathrm{~km}$ individual pursuit on track.

\section{Material and methods}

Participants. The qualified cyclists $(\mathrm{n}=14)$ participated in researches. In conducting surveys with the participation of athletes adhered to the Helsinki Declaration of 2000, directive № 86/609 of the European Society on the participation of people in. biomedical researches.

Organization of a research. In vitro athletes performed work in two modes " $A$ " and "B". The modified stationary bicycle "Monark" was used. Athletes performed work identical in volume, but different in the modes of passing a distance. The work in the mode " $A$ " tended to increase in speed of pedalling to the middle of a distance and its step-by-step decrease by the end of the work. The work in the mode "B" had opposite direction - a pedalling speed decrease to the middle of a distance and increase it by the end.

It was applied a complex method to carrying out biomechanical researches [25, 26]. Dynamics of kinematic and dynamic characteristics of horizontal and vertical efforts of the athlete was analyzed. The features of bioelectric activity were also analyzed: quadriceps femoris and biceps femoris muscles of the thigh; calf muscles and tibialis anterior muscle of the right leg. It was defined: amplitude and oscillation frequency of biopotentials; rhythm structure of bioelectric activity; the integrated bioelectric activity of muscles. Indicators of efficiency and profitability of physical activity were calculated. The variability of the researched characteristics of motor actions was defined.
Statistic analysis. In processing the experimental data we defined average values of indicators and their errors $(\mathrm{X} \pm \mathrm{m})$, a level of distinction of averages and reliability of distinctions ( $t, p)$, set value of dispersion variant around average $(\sigma, \mathrm{CV})$, defined a correlation level between the researched indicators $(r)$.

\section{Results}

The feature of cyclists" work in the mode " $\mathrm{A}$ " is a higher average speed of passing a competitive distance (in comparison with the mode "B"). The distinction of speeds was 7,5\%. Work in the mode " $\mathrm{A}$ " is characterized by increase in pedalling speed by the end of the first half of a distance (fig. 1, in comparison with an initial part) for $5 \%$; decrease in the speed of pedalling by the time of end of the $3 \mathrm{rd} \mathrm{km}$; stabilization of pedalling speed on the last kilometer of a distance.

Performance of work in the mode " $\mathrm{B}$ " is connected with essential (in comparison with an initial part) decrease by $15 \%$ of pedalling speed by the end of the second kilometer of a distance; with stabilization of pedalling rate on $3 \mathrm{rd} \mathrm{km}$; essential increase in pedalling rate on the finish (fig. 1). Work in the mode " $\mathrm{A}$ " is accompanied by the essential increase (by 15,4\%, in comparison with work in the mode " $\mathrm{B}$ ") in values of a total impulse of force (tab. $1)$. The volume of external mechanical work of cyclists was identical. The high efficiency of muscular activity was shown by athletes in the mode " $\mathrm{B}$ ". It is occurred due to change of pedalling type. The characteristic feature of pedalling was increased in the relative use of horizontal efforts (forwardstroke).

On the first kilometer of a distance in the mode " $\mathrm{A}$ " the total impulse of forces is defined by the value of efforts of downstroke and backstroke (38,7\% and 32,7\% respectively, tab. 2). On the $2^{\text {nd }} \mathrm{km}$ there is a redistribution of a relative impulse force towards essential increase in efforts of forwardstroke (up to $54,6 \%$ ). At the same time the force impulse of backstroke decreases (up to $2,1 \%$ ).

It is observed the considerable decrease in a total

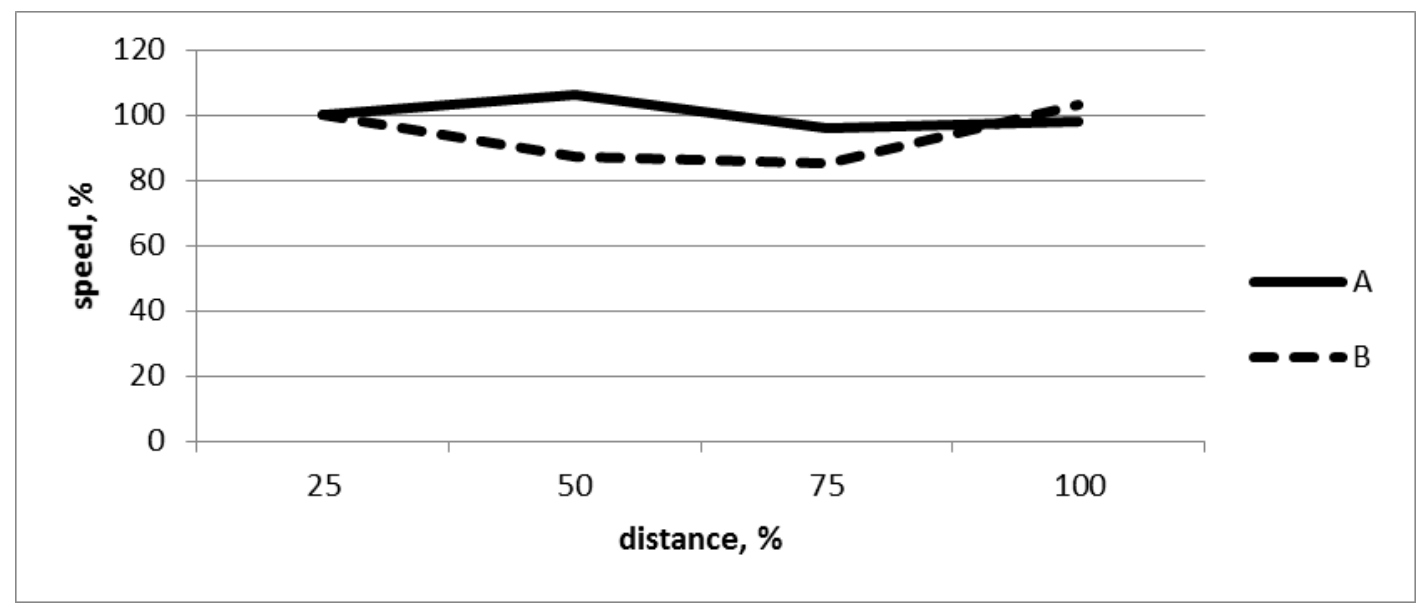

Figure. 1. Dynamics of speed of passing $4 \mathrm{~km}$ distance in various modes of muscular activity. Note: initial speed is considered as $100 \%$. 
Table 1. Indicators of pedalling speed dynamics, integrated biomechanical characteristics of cyclists motor actions in passing a $4 \mathrm{~km}$ distance

\begin{tabular}{|c|c|c|c|c|c|}
\hline Indicator & $\begin{array}{l}\text { Distance, } \\
\text { km }\end{array}$ & $\begin{array}{l}\text { Measure of } \\
\text { pedalling speed, } \\
(\%)\end{array}$ & $\begin{array}{l}\text { Coefficient of } \\
\text { efficiency of } \\
\text { action forces, (\%) }\end{array}$ & $\begin{array}{l}\text { Total impulse } \\
\text { of force, } \\
\text { (Hxsec) }\end{array}$ & $\begin{array}{l}\text { Total bioelectric } \\
\text { activity, (mkV/ } \\
\text { sec) }\end{array}$ \\
\hline \multirow{4}{*}{ Mode «A» } & 1 & 100 & 94,5 & 234,8 & 414,7 \\
\hline & 2 & +5 & 82,7 & 236,2 & 422,0 \\
\hline & 3 & -5 & 84,0 & 182,8 & 490,6 \\
\hline & 4 & -3 & 79,6 & 159,0 & 660,0 \\
\hline \multicolumn{2}{|c|}{ Total value of a distance } & - & $87,5 \pm 8,5 *$ & $812,8 * *$ & $1987,3 * *$ \\
\hline \multirow{4}{*}{ Mode «B» } & 1 & 100 & 79,0 & 162,6 & 472,3 \\
\hline & 2 & -15 & 83,6 & 160,8 & 556,5 \\
\hline & 3 & -16 & 69,6 & 231,6 & 492,8 \\
\hline & 4 & +1 & 71,0 & 132,6 & 455,4 \\
\hline \multicolumn{2}{|c|}{ Total value of a distance } & - & $76,0 \pm 7,0 *$ & $687,6 * *$ & $1977,0 * *$ \\
\hline \multicolumn{2}{|c|}{$\begin{array}{l}\text { Difference of values } \\
« A »-« B »(\%)\end{array}$} & $-7,7$ & $-13,0$ & $-15,4$ & $-0,5$ \\
\hline
\end{tabular}

Notes: * - average values of dispersion $\mathrm{X} \pm \mathrm{m} ; * *$ - total value of a distance

Table 2. Dynamics of indicators of relative use of efforts in a pedalling cycle during passing a $4 \mathrm{~km}$ distance, $(X \pm m)$

\begin{tabular}{|c|c|c|c|c|c|c|}
\hline \multirow{2}{*}{ Indicators } & \multirow{2}{*}{$\begin{array}{l}\text { Total impulse } \\
\text { of forces for } \\
\text { a distance, } \\
\text { (Hxsec) }\end{array}$} & \multirow{2}{*}{$\begin{array}{l}\text { Distance, } \\
\text { km }\end{array}$} & \multicolumn{4}{|c|}{ Relative impulse of forces, (\%) } \\
\hline & & & downstroke & upstroke & forwardstroke & backstroke \\
\hline \multirow{4}{*}{ Mode «A» } & & 1 & 38,7 & 13,6 & 15,0 & 32,7 \\
\hline & & 2 & 17,1 & 26,1 & 54,6 & 2,1 \\
\hline & & 3 & 23,0 & 43,4 & 10,6 & 23,0 \\
\hline & & 4 & 28,9 & 20,9 & 34,5 & 15,7 \\
\hline \multicolumn{3}{|c|}{ Average values of distance } & 26,9 & 26,0 & 28,7 & 18,5 \\
\hline \multirow{4}{*}{ Mode «B» } & & 1 & 19,2 & 12,5 & 40,4 & 27,9 \\
\hline & & 2 & 27,5 & 20,8 & 34,8 & 16,9 \\
\hline & & 3 & 40,4 & 31,3 & 22,6 & 5,6 \\
\hline & & 4 & 36,8 & 8,3 & 32,6 & 22,3 \\
\hline \multicolumn{3}{|c|}{ Average values of distance } & 31,0 & 18,2 & 32,6 & 18,2 \\
\hline
\end{tabular}

impulse of force in a pedalling cycle on the second half of a distance in the mode " $\mathrm{A}$ ". It occurs due to decrease in force impulse of forwardstroke by $10,6 \%$. On this part of a distance the relative share of efforts of backstroke decreases (up to 23,0\%), upstroke (up to 43,4\%) and the downstroke (up to $23,0 \%$ ). It is observed the further decrease in values of a total impulse of forces by the end of a distance. It is caused by the decrease in efforts of upstroke and backstroke (tab. 2).

On the $1 \mathrm{st} \mathrm{km}$ of a distance in the mode " $\mathrm{B}$ " the total forces impulse is significantly less, than in the mode " $\mathrm{A}$ ". It is connected with the insignificant use of downstroke and upstroke efforts. At the same time, there is an essential increase in forwardstroke efforts (up to $40,4 \%$ ). On the 2nd kilometer there is a redistribution of a relative forces impulse towards the decrease in efforts of forwardstroke (up to $34,8 \%$ ), backstroke (up to $16,9 \%$ ) and increase in force impulse of downstroke (up to $27,5 \%$ ) and upstroke (up to $20,8 \%$ ). At the same time, the total impulse of force in the mode " $\mathrm{B}$ " is less in $28,0 \%$, than during the work in the mode " $A$ ".

The total forces impulse during pedalling in the mode " $\mathrm{B}$ " considerably increases in the second half of a distance (in comparison with the mode "A"). It is defined by an increase in a force impulse of downstroke (up to $40,4 \%$ ) and upstroke (up to $31,3 \%$ ). On a finishing part is observed the decrease in a total force impulse. The impulse value doesn't depend on the modes of passing a distance. In the work of the mode " $\mathrm{B}$ " this decrease is more expressed (tab. 2). It is observed the considerable increase in the value of horizontal efforts in the mode " $\mathrm{B}$ ".

In the course of work performance of in various modes, there is a constant redistribution of shares of the relative use of efforts. The average data values of the relative use of forces impulse of downstroke, upstroke and forwardstroke in the mode "A" are equal. The value of backstroke decreases a little. It witnesses about a tendency to "spin" pedalling. It was the reason of more effective work in the mode " $\mathrm{A}$ ". The work in the mode " $\mathrm{B}$ " is characterized by the emphasis on the use of efforts 
of downstroke and forwardstroke. At the same time values of upstroke and backstroke are decreased a little. It witnesses about a tendency to "impulse" pedalling. It was the reason of more economic work in the mode " $\mathrm{B}$ ".

The spatially-temporal characteristics of efforts remain not changed. They don't depend on the modes of muscular activity.

Distribution of total bioelectric effect of muscles on every part of a distance in various modes is unequally (tab. 3 ). It is observed the gradual increase and achievement of a maximum of total bioelectric effect in the mode " $\mathrm{A}$ ". It is observed the increase in total bioelectric effect to the middle of a distance and the subsequent decrease to the finish in the " $\mathrm{B}$ " mode. There is a redistribution of the relative bioelectric effect of muscles in the first half of a distance in the mode " $\mathrm{A}$ " in a pedalling cycle. It is shown in the increase in activity of biceps femoris (up to $43 \%$ ) and of the anterior femoral head (up to $27,2 \%$ ). It is revealed the decrease in the bioelectric effect of calf muscles and tibialis anterior muscle (up to $15,7 \%$ and $13,2 \%$ respectively).

It is observed the redistribution of the relative activity of muscles on the third kilometer of a distance in the mode "A": is watched. The redistribution leads to the increase in the bioelectric effect of a calf muscle (up to $25,4 \%$ ) and an anterior tibialis muscle (up to $18,9 \%$ ). At the same time, the bioelectric effect of biceps femoris considerably decreases (up to $28,5 \%$ ). The increase in the bioelectric effect of biceps femoris is observed on the final straight of a distance (up to $38,5 \%$ ).

It is observed the considerable decrease of the relative activity of anterior head of quadriceps femoris (up to $15,0 \%$ ) by the end of the first half of a distance (in comparison with the first kilometer) in the mode "B". Also, there is an increase in the bioelectric effect of anterior tibialis muscle (tab. 3). It is observed the decrease of relative activity of biceps femoris (up to $23,6 \%$ ) on the third kilometer. It is also observed the increase in this indicator (up to $29,9 \%$ ) of the calf muscle. By the end of a distance, it is observed: essential increase in activity of biceps femoris; the decrease of the value of the bioelectric activity of calf muscle (up to $18,8 \%$ ) and anterior tibialis muscle (up to $10,8 \%$ ). At the same time, the activity of anterior head of quadriceps femoris remains unchanged (throughout the duration of 3/4 distances).

Equal values of total bioelectric effect are reached by redistribution of the relative bioelectric activity value of muscles. The high shiftability of muscles is most characteristic of work in the mode "B". It should be considered as the demonstration of the expressed coordination reorganizations in the system. The purpose of such reorganization is saving a resultant dynamic component of work. The average value of amplitude and oscillation frequency of biopotentials of the researched muscles remain unchanged.

The work in the mode " $\mathrm{A}$ " is less efficient than in the mode " $\mathrm{B}$ ". Increase in efficiency of motor actions in the mode " $\mathrm{B}$ " is defined by more active involvement in the operation of efforts of downstroke and backstroke. The work in the mode " $\mathrm{A}$ " is characterized by the equal distribution of efforts in a pedalling cycle. The possibility of equal making efforts is less favorable type of pedalling.

\section{Discussion.}

Individual races are divided into two stages. It depends on tasks and the nature of the activity. At the first stage (in the preliminary race) the racer has to pass a distance the most rationally with the planned result. In the subsequent races, it is necessary to create the schedule to ensure win ahead of the opponent.

There are three the most widespread variants of efforts regulation during overcoming $4 \mathrm{~km}$ distance by the racer. In the first variant, the athlete passes the most part of a distance with a equal speed. The second variant presupposes moderate fast start, the subsequent decrease of speed and finishing acceleration on the last third of a distance. In the third variant, the racer tries to create a certain stock of time in the first half of a distance. On the

Table 3. Dynamics of indicators of bioelectric activity of muscles in a pedalling cycle during passing a $4 \mathrm{~km}$ distance, $\mathrm{X} \pm \mathrm{m}$ )

\begin{tabular}{|c|c|c|c|c|c|c|}
\hline \multirow[b]{2}{*}{ Indicators } & \multirow[b]{2}{*}{$\begin{array}{l}\text { Total } \\
\text { bioelectric } \\
\text { activity of } \\
\text { muscles }\end{array}$} & \multirow[b]{2}{*}{ Distance, km } & \multicolumn{3}{|c|}{ Relative bioelectric activity of muscles, (\%) } & \multirow[b]{2}{*}{$\begin{array}{l}\text { Anterior } \\
\text { tibialis } \\
\text { muscle }\end{array}$} \\
\hline & & & $\begin{array}{l}\text { Anterior } \\
\text { head of } \\
\text { quadriceps } \\
\text { femoris }\end{array}$ & Biceps femoris & Calf muscle & \\
\hline \multirow{4}{*}{ Mode "A» } & & 1 & 23,8 & 25,0 & 32,4 & 18,8 \\
\hline & & 2 & 27,2 & 43,7 & 15,7 & 13,2 \\
\hline & & 3 & 31,2 & 28,5 & 25,4 & 18,9 \\
\hline & & 4 & 19,0 & 38,5 & 20,0 & 22,5 \\
\hline \multicolumn{2}{|c|}{ Average values of a distance } & & 25,3 & 33,9 & 23,4 & 18,4 \\
\hline \multirow{4}{*}{\multicolumn{2}{|c|}{ Mode «B» }} & 1 & 37,7 & 29,3 & 24,8 & 8,2 \\
\hline & & 2 & 22,7 & 30,7 & 21,5 & 25,1 \\
\hline & & 3 & 23,7 & 23,6 & 29,9 & 26,9 \\
\hline & & 4 & 23,2 & 47,1 & 18,8 & 10,8 \\
\hline \multicolumn{3}{|c|}{ Average values of a distance } & 26,9 & 32,7 & 23,7 & 17,7 \\
\hline
\end{tabular}


second half of a distance, the athlete keeps the speed which decreases a little. In practice there is the fourth variant of passing a distance: it is irregular work. But it is rarely applicable. It is connected with numerous oscillations of speed which lead to decrease in the result.

The considerable impact on the choice of the variant is exerted by the weather conditions, track covering; position a track in relation to sea level; readiness of the racer; knowledge of the own opportunities; detailed data about the opponent $[27,28]$. The most effective is rather equal distribution of efforts in a distance. It serves as a positive factor for the achievement of the good result [4]. Equal schedules should be applied in preliminary races under conditions of insufficient preparation. Equal schedules should be applied by racers with excellent endurance, but insufficient high-speed qualities [29]. There are no absolutely equal schedules of passing a distance. Throughout a distance, the athlete periodically gets to various conditions of physical laws, centrifugal and centripetal forces [30]. It influences on the athlete's speed and intensity of work.

Recently the strongest athletes began to win in the World Cups and Olympic Games due to use of the second and third variants of schedules of passing a distance [5]. It has formed the basis for the choice as models the specified modes.

The highly-qualified cyclists have a variable distribution of efforts in the pursuit race. It is defined by specific features. Our data will be agreed with results of researches of other authors. Authors clarified that the beginning of a distance practically doesn't influence on the final result in $4 \mathrm{~km}$ individual pursuit race [4, 5, 31].

The highly-qualified athletes aren't able to keep identical motor characteristics during the whole time of passing a distance. The various researches observed different distinction of power types of pedalling [32-34]. Authors specify that work in an impulse mode promotes more efficient power consumption. It is necessary to In practice by a natural method to calculate average between “spin" and "impulse” type of pedalling [34].

The important point in the distribution of muscular efforts at the specific moment of passing a distance is the ability of athletes to correlate sporting technique to the functional capabilities of an organism.

The scientists determined [16, 17] that highlyqualified cyclists speed in the period of exhaustion is supported preferentially due to compensatory changes in contractions activities of muscles.

In the period of the strong exhaustion, athletes keep pedalling speed due to increase of efforts of working muscles [35]. It is one of the factors which define efficiency of motor actions [1, 20, 16, 17]. However, Ragimov RM [36] revealed that work with shifting is less effective. Pedalling with the considerable amplitude of shifting is less productive [34]. The more the intensity of oscillation amplitude increases in different options of variable work, the fewer time examinees are capable to stand it.

\section{Conclusions}

1. Received data should be considered as demonstration of specific features of passing a distance in the competitive modes.

2. The tactical variant of the competitive program creation is defined by a personal functional status.

3. The mode " $\mathrm{B}$ " is physiologically more favorable. The mode " $\mathrm{B}$ " should be considered as a model of passing a distance in preliminary races of personal pursuit.

4. The work in the mode " $A$ " requires the limit mobilization of organism functions. The work in the mode " $A$ " is more effective in the achievement of the sporting result. The work in the mode " $\mathrm{A}$ " can be used only once in the final race of competitions.

\section{Acknowledgments}

The author is grateful to Dyachenko V.F. (physiological researches), to Voloshin A.L. (biomechanical researches), Kompanchenko N.V. (biochemical researches) for their help in carrying out researches.

\section{Funding}

The author received no financial support for the research, authorship, and publication of this article.

\section{Conflicts of interest}

The authors declare that there is no conflict of interests. 


\section{References}

1. Alexandrov II, Mikhhaylova IN. Efficiency of the motor activity in cycling. Uchenye zapiski universiteta imeni P.F.Lesgafta, 2015;12(130):25-30. (in Russian)

2. Mujika I, Ronnestad BR, Martin DT. Effects of Increased Muscle Strength and Muscle Mass on Endurance-Cycling Performance. International Journal of Sports Physiology and Performance. 2016;11(3):283-289. doi:10.1123/ ijspp.2015-0405

3. Wangerin M, Schmitt S, Stapelfeldt B, Gollhofer A. Inverse dynamics in cycling performance. Advances in Medical Engineering, 2017;114:329-334.

4. Andrunin MA, Golovachev AI, Krylatyh UG, Utkin VL. Working efficiency of the cyclist in modeling $4 \mathrm{~km}$ individual pursuit with variants of forces distribution. Cycling, 1981;1:44-46. (in Russian)

5. Martynov VS. Model characteristics of competitive activity in cyclic sports. 1983. (in Russian)

6. Sigrist R, Dolder V, Riener R, Wolf P. Sonification in cycling - a feasibility study. X Symposium der dvs Sportinformatik, Vienna: Austria; 2014.

7. Dahmen T. Optimization of pacing strategies for cycling time trials using a smooth 6-parameter endurance model. PreOlympic Congress on Sports Science and Computer Science in Sport (IACSS2012). Liverpool: UK; 2012. P. 34-40.

8. Lukes R, Carre M, Haake S. Track Cycling: An Analytical Model. In Moritz EF, Haake S, editors. The Engineering of Sport, 2006;1:115-120.

9. Baechle TR, Earle RW. Essentials of strength training and conditioning. Human Kinetics, Champaign, United States, 2008.

10.Hanaki S,Robert S, Richard R. The effects of seat post angle in cycling performance. University of Kentucky: UKnowledge; 2012.

11.Wilson DG. Bicycling Science. The MIT Press; 2004.

12.Chhaidze LV. About control of the person's motor actions. Moscow: Physical Culture and Sport; 1970. (in Russian)

13.Turpin NA, Guével A, Durand S, Hug F. Fatigue related adaptions in muscle coordination during a cyclic exercise in humans. Journal of Experimental Biology, 2011;2:34-40.

14.Olds TS. Modelling human locomotion: applications to cycling. Sports Medicine 2001;31(7):497-502.

15.Dorel S, Drouet JM, Couturier A, Champoux Y. Changes of pedaling technique and muscle coordination during an exhaustive exercise. Medicine and Science in Sports and Exercise, 2009;41(6):1277-1286.

16.Monogarov VD, Bratkovsky VK. Coordination motions of sportsmen in the period of the compensated fatigue during muscular work of cyclic character. Kiev; 1979. (in Russian)

17.Ema R, Wakahara T, Yanaka T, Kanehisa H, Kawakami Y. Unique muscularity in cyclists' thigh and trunk: A crosssectional and longitudinal study. Scandinavian Journal of Medicine \& Science in Sports. 2016;26(7):782-793. doi:10.1111/sms.12511

18.Thomas K, Lee M, Ian M, James C. Effect of Pedaling Technique on Mechanical Effectiveness and Efficiency in Cyclists, Medicine Science. Sports Exercise, 2007;39:991995.

19.Theurel J, Crepin M, Foissac M, Temprado JJ. Effects of different pedalling techniques on muscle fatigue and mechanical efficiency during prolonged cycling. Scandinavian Journal of Medicine and Science in Sports, 2011;22:714-721.
20.Bini RR, Rossato M. Kinetics and Pedaling Technique. Biomechanics of Cycling. Springer International Publishing Switzerland; 2014.

21.Lépine J, Champoux Y, Drouet J-M. Technique to Measure the Dynamic Behavior of Road Bike Wheels. Topics in Modal Analysis, 2012;II;6:465-470.

22.Hug F, Turpin NA, Guevel A, Dorel S. Is interindividual variability of EMG patterns in trained cyclists related to different muscle synergies? Journal of Applied Physiology, 2010;108:1727-1736.

23.Crouch TN, Burton D, Thompson M, Martin DT, Brown NAT, Sheridan J. A phase-averaged analysis of the pedalling cyclist wake. 19 th Australian Fluid Mechanics Conference, Melbourne: Australia; 2014. P.100-105.

24.Mornieux G, Gollhofer A, Staperlfeldt B. Muscle coordination while pulling up during cycling. International Journal of Sports Medicine, 2010;31:843-846.

25. Walsh JA, Dawber JP, Lepers R, Brown M, Stapley PJ. Is Moderate Intensity Cycling Sufficient to Induce Cardiorespiratory and Biomechanical Modifications of Subsequent Running? Journal of Strength and Conditioning Research. 2017;31(4):1078-1086. doi:10.1519/ jsc.0000000000001556

26.Slater LV, Simpson AS, Blemker SS, Hertel J, Saliba SA, Weltman AL, et al. Biomechanical adaptations during running differ based on type of exercise and fitness level. Gait \& Posture. 2018;60:35-40. doi:10.1016/j.gaitpost.2017.11.012

27.Broker JP, Kyle CR, Burke ER. Racing cyclist power requirements in the $4000 \mathrm{~m}$ individual and team pursuits. Medicine and Science in Sports and Exercise 1999;31(11):2330

28.Golovachev AI, Krylatyh UG. Control of tactical readiness of young cyclists in individual pursuit. Cycling, 1982; 1:4246. (in Russian)

29.Erik WF, Daryl LP, Irvin EF. The science of cycling: Factors Affecting Performance. Sports Medicine, 2005;35:313-337.

30.Castronovo AM, De Marchis C, Bibbo D, Conforto S, Schmid M, D’Alessio T. Neuromuscular adaptations during submaximal prolonged cycling. Conf. Proc. IEEE Medicine Engineering and Biology Society, 2012. P. 3612-3615.

31.Sundström D, Carlsson P, Tinnsten M. On Optimization of Pacing Strategy in Road Cycling. Procedia Engineering, 2013;60:118-123.

32.Martynov GM, Abrosimov VV. Electromyographic and dynamic characteristics of push and spin ways of pedalling. VII Conference of Young Scientists, 1970. P. 148-150. (in Russian)

33.Erdakov SV. About stability of motor actions skills in cyclic sports. Teoriia i praktika fizicheskoj kul tury, 1972;8:14-15. (in Russian)

34.Mihaylov VV, Levenko NA. Physiological prerequisites of the optimum choice of pedalling rate. Cycling, 1975;1:5-8. (in Russian)

35.Umberto E, Tamara H, Jachen D. Influence of racing position on cycling patterns, Portuguese Journal of Sport Sciences, 2011;11:211-214.

36. Ragimov RM. Efficiency of cyclists in various combinations of frequency of pedalling and efforts to pedals. Cycling, 1966;1:93-101. (in Russian) 


\section{Information about the authors:}

Kolumbet A.N. (Corresponding author) ; http://orcid.org/0000-0001-8775-4232; re_play@3g.ua; Department of Physical Education and Health, Kiev National University of Technology and Design; st. Nemirovich-Danchenko, 2, Kiev, 14013, Ukraine.

Dudorova L.Y.; http://orcid.org/0000-0002-6263-4995; vykh46@i.ua; Department of Physical Education and Health, Kiev National University of Technology and Design; st. Nemirovich-Danchenko, 2, Kiev, 14013, Ukraine.

Babina N.A.; http://orcid.org/0000-0001-9777-4827; babynatg @3mail.ru; Department of Economics, Kiev National University of Technology and Design; st. Nemirovich-Danchenko, 2, Kiev, 14013, Ukraine.

Natroshvili S.G.; http://orcid.org/0000-0002-1598-4589; babynatg @3mail.ru; Department of Economics, Kiev National University of Technology and Design; st. Nemirovich-Danchenko, 2, Kiev, 14013, Ukraine.

Chernovsky S.M.; http://orcid.org/0000-0002-1927-9203; chernovskij.sm@knutd.com.ua; Department of Physical Education and Health, Kiev National University of Technology and Design; st. Nemirovich-Danchenko, 2, Kiev, 14013, Ukraine.

Cite this article as: Kolumbet AN, Dudorova LY, Babina NA, Natroshvili SG, Chernovsky SM. Biomechanical justification of the choice of optimum mode for passing the individual pursuit race. Physical education of students, 2018;22(2):70-76. doi: $10.15561 / 20755279.2018 .0203$

The electronic version of this article is the complete one and can be found online at: http://www.sportedu.org.ua/index.php/PES/issue/archive

This is an Open Access article distributed under the terms of the Creative Commons Attribution License, which permits unrestricted use, distribution, and reproduction in any medium, provided the original work is properly cited (http://creativecommons.org/licenses/by/4.0/deed.en).

Received: 27.12.2017

Accepted: 19.01.2018; Published: 27.04.2018 